\title{
Peripheral neuropathy in mice with neuronal nitric oxide synthase gene deficiency
}

\author{
IGOR VARENIUK ${ }^{1}$, PAL PACHER ${ }^{2}$, IVAN A. PAVLOV ${ }^{1}$, VIKTOR R. DREL $^{1}$ and IRINA G. OBROSOVA ${ }^{1}$ \\ ${ }^{1}$ Pennington Biomedical Research Center, Louisiana State University System, Baton Rouge, LA; ${ }^{2}$ Section on \\ Oxidative Stress Tissue Injury, Laboratory of Physiological Studies, NIH/NIAAA, Bethesda, MD, USA
}

Received December 29, 2008; Accepted January 26, 2009

DOI: 10.3892/ijmm_00000166

\begin{abstract}
Evidence for the important role of the potent oxidant peroxynitrite in peripheral diabetic neuropathy and neuropathic pain is emerging. This study evaluated the contribution of neuronal nitric oxide synthase (nNOS) to diabetes-induced nitrosative stress in peripheral nerve and dorsal root ganglia, and peripheral nerve dysfunction and degeneration. Control and $\mathrm{nNOS}^{-/-}$mice were made diabetic with streptozotocin, and maintained for 6 weeks. Peroxynitrite injury was assessed by nitrotyrosine and poly(ADP-ribose) immunoreactivities. Peripheral diabetic neuropathy was evaluated by measurements of sciatic motor and hind-limb digital sensory nerve conduction velocities, thermal algesia, tactile allodynia, and intraepidermal nerve fiber density. Control $\mathrm{nNOS}^{-/-}$mice displayed normal motor nerve conduction velocity and thermal response latency, whereas sensory nerve conduction velocity was slightly lower compared with non-diabetic wild-type mice, and tactile response threshold and intraepidermal nerve fiber density were reduced by 47 and 38\%, respectively. Both diabetic wild-type and $\mathrm{nNOS}^{-/}$mice displayed enhanced nitrosative stress in peripheral nerve. In contrast to diabetic wild-type mice, diabetic nNOS ${ }^{-/-}$mice had near normal nitrotyrosine and poly(ADP-ribose) immunofluorescence in dorsal root ganglia. Both diabetic wild-type and $\mathrm{nNOS}^{--}$mice developed motor and sensory nerve conduction velocity deficits and thermal hypoalgesia although nNOS gene deficiency slightly reduced severity of the three disorders. Tactile response thresholds were similarly decreased in control and diabetic $\mathrm{nNOS}^{-/-}$mice compared with non-diabetic wild-type mice. Intraepidermal nerve fiber density was lower by $27 \%$ in diabetic $\mathrm{nNOS}^{-/-}$mice compared with the corresponding nondiabetic group, and by $20 \%$ in diabetic nNOS s $^{-/-}$mice
\end{abstract}

Correspondence to: Dr Irina G. Obrosova, Pennington Biomedical Research Center, Louisiana State University, 6400 Perkins Road, Baton Rouge, LA 70808, USA

E-mail: obrosoig@pbrc.edu

Key words: nerve conduction, neuronal nitric oxide synthase, nitrosative stress, peripheral diabetic neuropathy, streptozotocindiabetic mouse compared with diabetic wild-type mice. In conclusion, nNOS is required for maintaining the normal peripheral nerve function and small sensory nerve fibre innervation. nNOS gene deficiency does not protect from development of nerve conduction deficit, sensory neuropathy and intraepidermal nerve fiber loss.

\section{Introduction}

Accumulation of the potent oxidant peroxynitrite, a product of superoxide anion radical reaction with nitric oxide, is associated with multiple detrimental consequences including, but not limited by, initiation of lipid peroxidation, DNA breakage and base modifications, metalloproteinase and poly(ADP-ribose) polymerase (PARP) activations, impairment of cell signaling, changes in transcriptional regulation, inflammatory response, and, in extreme cases, cell death by necrosis and apoptosis (1-4). Evidence for the important role of peroxynitrite in diabetic complications including vascular disease (5), cardiomyopathy (2-4), peripheral (PDN; 6-11) and autonomic (12) neuropathy, and retinopathy (13) is emerging. Using a pharmacological approach with structurally different peroxynitrite decomposition catalysts and several animal models of diabetic neuropathy, we demonstrated an important role for peroxynitrite injury (nitrosative stress) in diabetes-associated nerve blood flow and nerve conduction deficits, impaired vascular reactivity of epineurial arterioles, thermal hyper- and hypoalgesia, mechanical hypoalgesia, tactile allodynia, and small sensory nerve fiber degeneration (6-11). Furthermore, nitrosative stress in peripheral nerve, spinal cord, and dorsal root ganglion (DRG) neurons has been identified as an important factor leading to PARP activation, another important mechanism in the pathogenesis of PDN (14-17).

Until now, the sources of superoxide and nitric oxide for diabetes-related peroxynitrite formation in peripheral nervous system (PNS) have been elusive. Two pharmacological studies $(18,19)$ revealing beneficial effects of the NAD $(\mathrm{P}) \mathrm{H}$ oxidase inhibitor apocynin and the xanthine oxidase inhibitor allopurinol on early PDN, suggest that these two superoxidegenerating enzymes contribute to diabetes-associated superoxide production in PNS. Increased superoxide production has been documented in vasa nervorum in rat models of both Type 1 and Type 2 diabetes $(16,20,21)$, and in high glucoseexposed human Schwann cells (22). Superoxide dismutase 
activity was found to be reduced in the diabetic nerve $(23,24)$. Insufficient information is available on the role of individual isoforms of nitric oxide synthase (NOS), an enzyme producing the second component for peroxynitrite formation, i.e., nitric oxide, in nitrosative stress in PNS and PDN. Endothelial NOS (eNOS) is known to play an important role in maintenance of normal nerve blood flow, and its uncoupling in diabetes causes neurovascular dysfunction and nerve conduction deficits $(25,26)$. Inducible NOS (iNOS) has recently been identified as a major contributor to oxidativenitrosative stress in peripheral nerve as well as nerve conduction deficit, sensory disorders, and intraepidermal nerve fiber loss characteristic for PDN (12). The present study was aimed at evaluating the role for neuronal NOS (nNOS) in oxidative-nitrosative stress in peripheral nerve and DRG, and in development of neuropathic changes in STZ-diabetic mice, a model of Type 1 diabetic neuropathy. STZ-induced diabetic mice of all genetic strains studied so far, i.e., C57B16/J $(6,8,9,12,27-30), 129 \mathrm{~S} 1 / \mathrm{SvImJ}$ (17), Swiss-Webster (31,32), and C57B6:129S7 (33) mice, developed both functional and structural changes characteristic for PDN.

\section{Materials and methods}

Reagents. Unless otherwise stated, all chemicals were of reagent-grade quality, and were purchased from Sigma Chemical Co., St. Louis, MO. Rabbit polyclonal antinitrotyrosine (NT) antibody was purchased from Upstate, Lake Placid, NY, and mouse monoclonal anti-poly(ADPribose) from Trevigen, Inc., Gaithersburg, MD. Secondary Alexa Fluor 488 goat anti-rabbit and Alexa Fluor 488 goat anti-mouse antibodies as well as Prolong Gold Antifade Reagent were purchased from Invitrogen, Eugene, OR. Avidin/ Biotin Blocking Kit, M.O.M. Basic Kit, Vectastain Elite ABC Kit (Standard*), DAB Substrate Kit, and 3,3'-diaminobenzidine were obtained from Vector Laboratories, Burlingame, CA. Rabbit polyclonal anti-protein gene product 9.5 (ubiquitin c-terminal hydrolase) antibody was purchased from Chemicon International, Inc., Temecula, CA. Other reagents for immunohistochemistry were purchased from Dako Laboratories, Inc., Santa Barbara, CA.

Animals and limitations of the $\mathrm{NOS}^{-/}$mouse model. The experiments were performed in accordance with regulations specified by the National Institutes of Health 'Principles of Laboratory Animal Care, 1985 Revised Version' and Pennington Biomedical Research Center Protocol for Animal Studies. Several breeding pairs of B6.129S4-Nos $1^{\text {tmlPlh } / J}$ $\left(\mathrm{nNOS}^{-/}\right)$mice, C57B16/J background, were obtained from Jackson Laboratories (Bar Harbor, ME, stock number 002986). The use of $\mathrm{nNOS}^{-/-}$mice for diabetic neuropathyrelated studies is associated with some limitations. nNOSdeficient mice have enlarged stomachs, and a significant proportion develops a gastroparesis-like condition in both non-diabetic and diabetic states. Furthermore, hyperglycemiceuglycemic clamp studies demonstrate that homozygotes exhibit insulin resistance at the level of peripheral tissues (http://jaxmice.jax.org/strain/002986.html).

For the main experiment, a colony of $\mathrm{nNOS}^{-/-}$mice was established at Pennington Biomedical Research Center.
Mature male C57B16/J mice were purchased from Jackson Laboratories and served as controls. All the mice were fed standard mouse chow (PMI Nutrition International, Brentwood, MO) and had access to water ad libitum. Diabetes was induced by a single injection of streptozotocin (STZ), $100 \mathrm{mgkg}^{-1} \mathrm{~d}^{-1}$, i.p., to non-fasted animals. Blood samples for glucose measurements were taken from the tail vein three days after STZ injection and the day before the animals were sacrificed. The mice with blood glucose $\geq 13.8 \mathrm{mM}$ were considered diabetic. The injected mice that had blood glucose concentration in non-diabetic range have been given low-dose STZ injections (40 $\mathrm{mgkg}^{-1} \mathrm{~d}^{-1}$, i.p.) until they developed hyperglycemia (typically, one-three additional injections). At the end of the study (6-week duration of diabetes), the physiological and behavioral tests were performed in the following order: tactile responses to flexible von Frey filaments (first day), thermal algesia by tail-flick test (second day), thermal algesia by paw withdrawal test (third day), SNCV and MNCV (fourth day). Measurements of MNCV and SNCV were performed in mice anaesthetized with a mixture of ketamine and xylazine $\left(45 \mathrm{mgkg}^{-1}\right.$ body weight and $15 \mathrm{mgkg}^{-1}$ body weight, respectively, i.p.).

Anesthesia, euthanasia and tissue sampling. The animals were sedated by $\mathrm{CO}_{2}$, and immediately sacrificed by cervical dislocation. Sciatic nerves, dorsal root ganglia (DRG), and foot pads were fixed in normal buffered $4 \%$ formalin for assessment of nitrotyrosine and poly(ADP-ribose) by immunofluorescent histochemistry and intraepidermal nerve fiber density by conventional immunohistochemistry. Poly(ADPribose) abundance is a measure of poly(ADP-ribose) polymerase activity $(14-17,34)$.

\section{Specific methods}

Physiological tests. Sciatic MNCV and hind-limb digital SNCV were measured as we have described elsewhere $(11,14,17)$.

\section{Behavioral tests}

i) Tactile response threshold. Tactile responses were evaluated by quantifying the withdrawal threshold of the hindpaw in response to stimulation with flexible von Frey filaments as we have described (35).

ii) Thermal algesia. The paw withdrawal latency in response to the radiant heat $(15 \%$ intensity which produced a heating rate of $\sim 1.3^{\circ} \mathrm{C}$ per sec, cut-off time $30 \mathrm{sec}$ ) was determined as we have described $(7-9,17,35)$ using the IITC model 336 TG combination tail-flick and paw algesia meter (IITC Life Science) with a floor temperature $\sim 32-33^{\circ} \mathrm{C}$ (manufacturer's set up). For assessment of tail flick response latencies, the device was set at $40 \%$ heating intensity (heating rate $\sim 2.5^{\circ} \mathrm{C}$ per sec) with a cut-off at $10 \mathrm{sec}$. In both tests, at least three readings per animal were taken at $15 \mathrm{~min}$ interval, and the average was calculated.

Immunohistochemical studies. All sections were processed by a single investigator and evaluated blindly. Low power observations of skin sections stained for PGP 9.5 were made using a Zeiss Axioskop microscope. Color images were captured with a Zeiss Axiocam HRc CCD camera at 
Table I. Initial and final body weights and blood glucose concentrations in experimental groups.

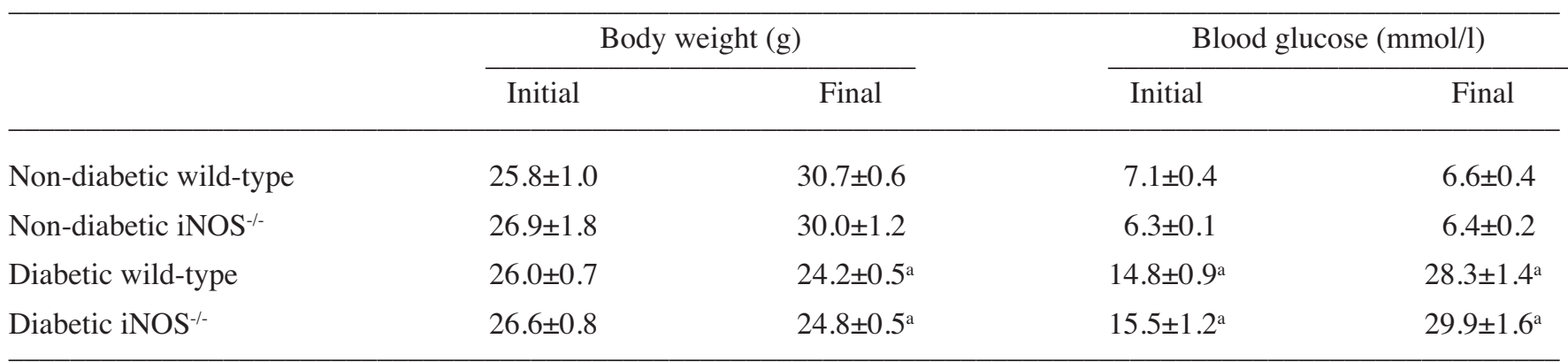

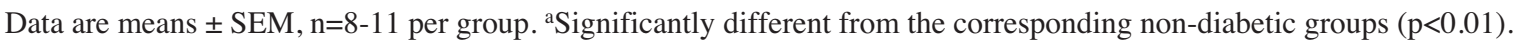

$1300 \times 1030$ resolution. Low power images were generated with a 40x acroplan objective using the automatic capturing feature of the Zeiss Axiovision software (Ver. 3.1.2.1). Low power observations of sciatic nerve sections stained for NT and DRG sections stained for NT and poly(ADP-ribose) were made using a Zeiss Axioplan 2 imaging microscope. Color images were captured with a Photometric CoolSNAPтм HQ CCD camera at $1392 \times 1040$ resolution. Low power images were generated with a 40x acroplan objective using the RS Image $^{\mathrm{TM}}$ 1.9.2 software.

i) NT immunoreactivity in sciatic nerve and $D R G$ neurons. NT immunoreactivities in the sciatic nerve and DRG were assessed by immunofluorescent histochemistry. In brief, sections were deparaffinized in xylene, rehydrated in decreasing concentrations of ethanol, and washed in water. For immunofluorescent histochemistry, rabbit polyclonal anti-NT antibody was used in a working dilution 1:400. Primary antibody was omitted in negative controls. Secondary Alexa Fluor 488 goat anti-rabbit antibody was applied in a working dilution 1:200. Sections were mounted in Prolong Gold Antifade Reagent. The intensity of fluorescence was quantified using the ImageJ 1.32 software (National Institutes of Health, Bethesda, MD) and expressed as mean \pm SEM for each experimental group.

ii) Poly(ADP-ribose) (PAR) immunoreactivity in DRG. PAR immunoreactivity was assessed as described (14) with minor modifications. In brief, sections of DRG were deparaffinized in xylene, rehydrated in decreasing concentrations of ethanol and washed in water. Non-specific binding was blocked with the mouse IG blocking reagent supplied with the Vector M.O.M. Basic Immunodetection Kit. Then mouse monoclonal anti-PAR antibody was diluted 1:100 in 1\% BSA in TBS, and applied overnight at $4^{\circ} \mathrm{C}$ in a humidity chamber. Primary antibody was omitted in negative controls. Secondary Alexa Fluor 488 goat anti-mouse antibody was diluted 1:200 in TBS and applied for $2 \mathrm{~h}$ at room temperature. Sections were mounted in Prolong Gold Antifade Reagent. At least, ten fields of each section were examined to select one representative image. Representative images were micro-photographed and PAR fluorescence was calculated for each microphotograph using the ImageJ 1.32 software, and was expressed as mean \pm SEM for each experimental group. To evaluate neuronal PAR accumulation, a percentage of DRG neurons with weak, moderate, and intense PAR immunofluorescence was calculated for each experimental group. iii) Intraepidermal nerve fiber density (INFD). INFD was assessed as described $(7-9,11,17)$. Three randomly chosen $5-\mu \mathrm{m}$ sections from foodpad skin of each mouse were deparaffinized in xylene, hydrated in decreasing concentrations of ethanol, and washed in water. Non-specific binding was blocked by $10 \%$ goat serum containing $1 \%$ BSA in TBS (Dako, Carpinteria, CA) for $2 \mathrm{~h}$, and the Avidin/Biotin Blocking Kit, according to the manufacturer's instructions. Then, rabbit polyclonal anti-protein gene product 9.5 (ubiquitin c-terminal hydrolase) antibody was applied in 1:2000 dilution. Secondary biotinylated goat anti-rabbit $\operatorname{IgG}(\mathrm{H}+\mathrm{L})$ antibody was applied in 1:400 dilution, and the staining performed with the Vectastain Elite ABC Kit (Standard*). For visualization of specific binding sites, the DAB Substrate Kit containing 3,3-diaminobenzidine was used. Sections were counterstained with Gill's hematoxylin, dehydrated and mounted in Micromount mounting medium (Surgipath Medical Ind., Richmond, IL). Intraepidermal nerve fiber profiles were counted blindly by three independent investigators, under an Olympus BX-41 microscope, and the average values were used. Microphotographs of stained sections were taken on Axioscop 2 microscope (Zeiss) at magnification $\mathrm{x} 4$, and the length of epidermis was assessed with the ImagePro 3.0 program (Media Cybernetics). An average of $2.8 \pm 0.3 \mathrm{~mm}$ of the sample length was investigated to calculate a number of nerve fiber profiles per $\mathrm{mm}$ of epidermis.

Statistical analysis. The results are expressed as mean \pm SEM. Data were subjected to equality of variance F test, and then to log transformation, if necessary, before one-way analysis of variance. Where overall significance $(p<0.05)$ was attained, individual between group comparisons were made using the Student-Newman-Keuls multiple range test. Significance was defined at $\mathrm{p} \leq 0.05$. When between-group variance differences could not be normalized by log transformation (datasets for body weights and plasma glucose), the data were analyzed by the non-parametric Kruskal-Wallis one-way analysis of variance, followed by the Bonferroni/ Dunn test for multiple comparisons.

\section{Results}

Weight gain during the 6-week study was $19 \%$ in nondiabetic wild-type and $11.5 \%$ in non-diabetic $\mathrm{nNOS}^{-/-}$mice (Table I). Both diabetic wild-type and diabetic $\mathrm{nNOS}^{-/-}$mice lost $7 \%$ of their initial body weights. Initial (after STZ 

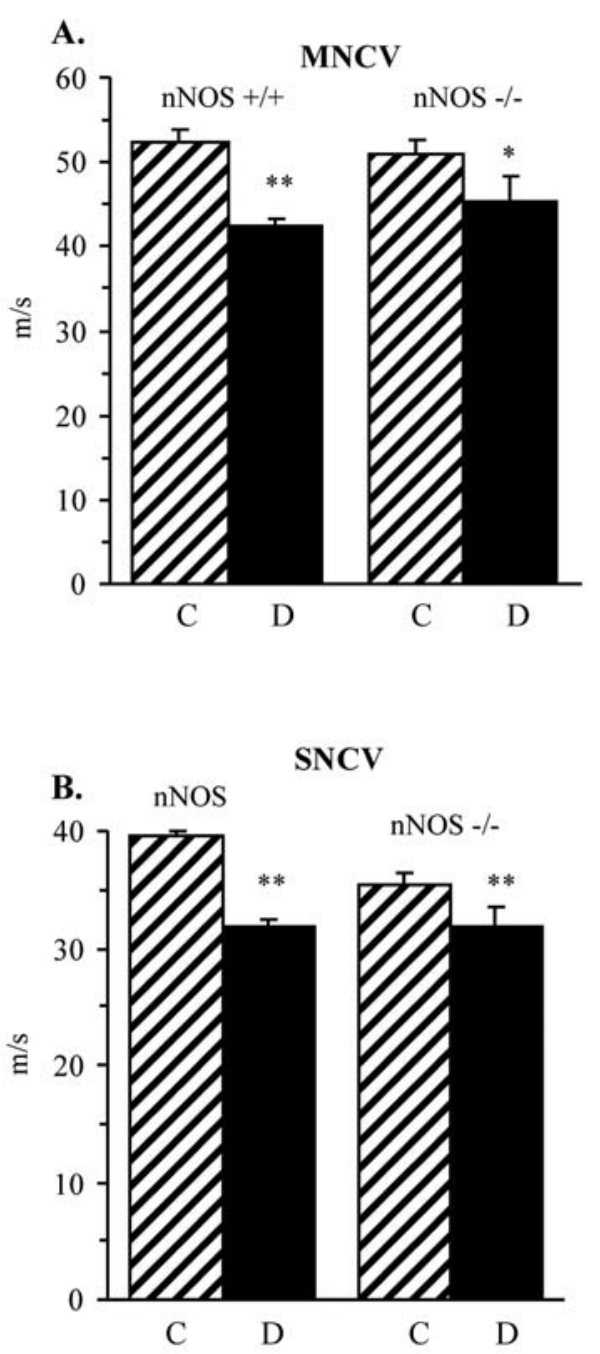

Figure 1. Sciatic motor nerve conduction velocities (A) and hind-limb digital sensory nerve conduction velocities (B) in control and diabetic wildtype and $\mathrm{nNOS}^{-/}$mice. Mean \pm SEM, $\mathrm{n}=8-10$ per group. $\mathrm{C}$, control mice; $\mathrm{D}$, diabetic mice. ${ }^{*} \mathrm{p}<0.05$ and ${ }^{* *} \mathrm{p}<0.01$ vs corresponding non-diabetic groups.

injection) blood glucose concentrations were 108 and $146 \%$ higher in diabetic wild-type and diabetic nNOS ${ }^{-/}$mice compared with the corresponding controls. Hyperglycemia progressed with the prolongation of diabetes. Final blood glucose concentrations were similar in diabetic wild-type and diabetic nNOS $^{-/-}$mice.

nNOS gene deficiency did not affect sciatic MNCV and resulted in $11 \%$ reduction in hind-limb SNCV in non-diabetic mice (Fig. 1). MNCV and SNCV were 19 and 20\% lower in diabetic wild-type mice ( $\mathrm{p}<0.01$ for both comparisons), and 11 and $10 \%$ lower in diabetic nNOS $^{-/-}$mice $(\mathrm{p}<0.05$ and $<0.01$, respectively), compared with the corresponding nondiabetic groups.

The latency of hind paw withdrawal in response to radiant heat was increased by $100 \%$ in diabetic wild-type mice compared with the control group $(\mathrm{p}<0.01)$, consistent with clearly manifest thermal hypoalgesia (Fig. 2A). This is in agreement with the results of tail-flick test which also revealed increased thermal response latencies in the diabetic wild-type mice (Fig. 2B). The severity of hypoalgesia by paw withdrawal test was lower in diabetic nNOS $^{-/-}$mice, compared with diabetic wild-type mice.

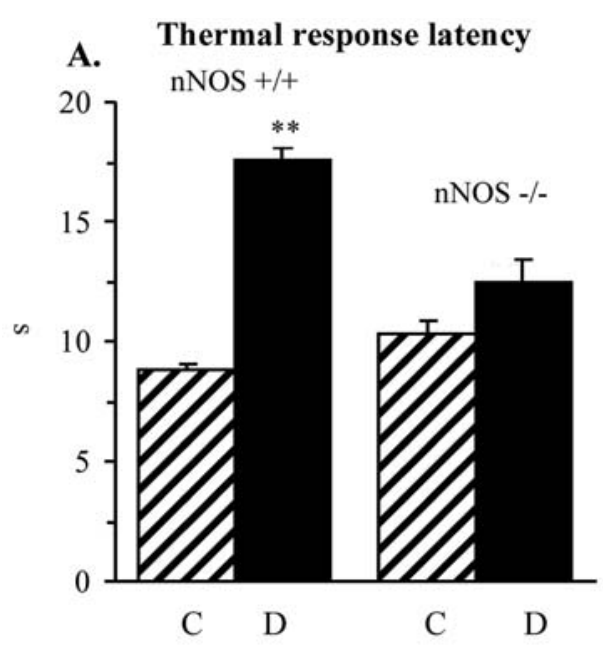

Tail Flick response latency

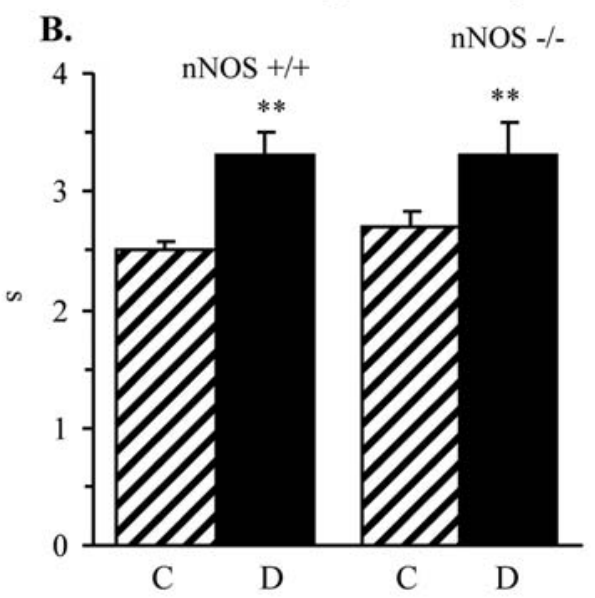

Figure 2. Paw withdrawal latencies in response to radiant heat (A) and tail-flick test response latencies (B) in control and diabetic wild-type and $\mathrm{nNOS}^{-/-}$mice. Mean \pm SEM, n=8-11 per group. C, control mice; $\mathrm{D}$, diabetic mice. ${ }^{* *} \mathrm{p}<0.01$ vs corresponding non-diabetic groups; ${ }^{* \#} \mathrm{p}<0.01$ vs diabetic wild-type mice.

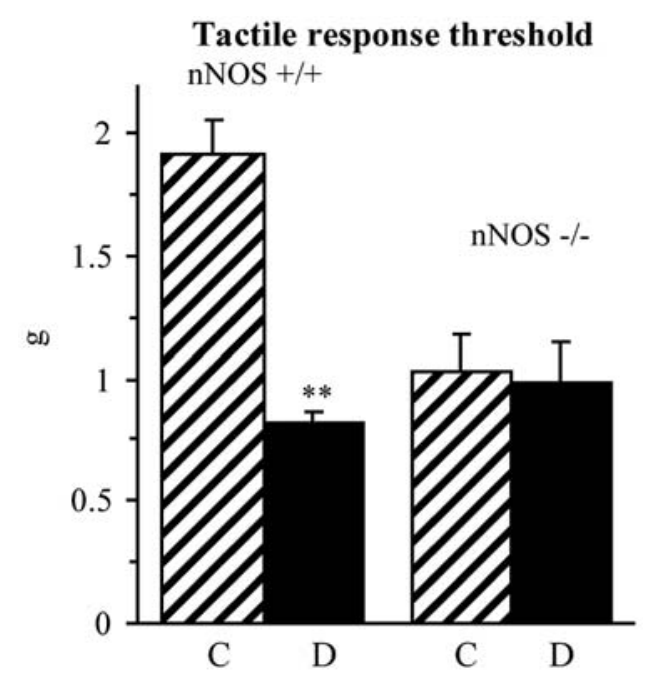

Figure 3. Tactile response thresholds in response to stimulation with flexible von Frey filaments in control and diabetic wild-type and $\mathrm{nNOS}^{-/-}$mice Mean \pm SEM, $n=8-11$ per group. $C$, control mice; $D$, diabetic mice. ${ }^{* *} \mathrm{p}<0.01$ vs non-diabetic control mice. 
A.

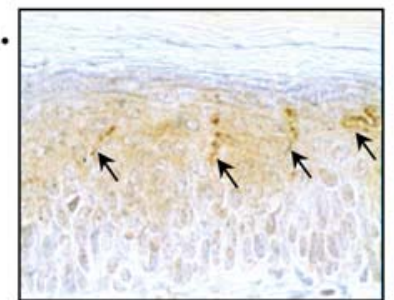

$\mathrm{C}(\mathrm{nNOS}+/+)$

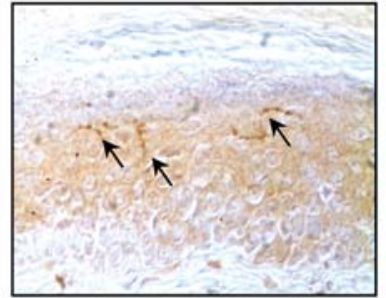

C (nNOS -/-)

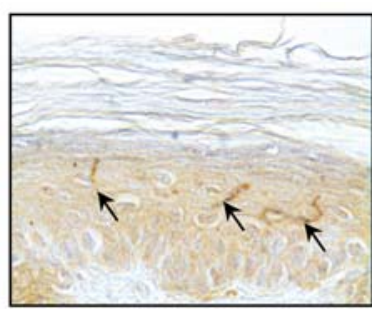

D $($ nNOS +/+)

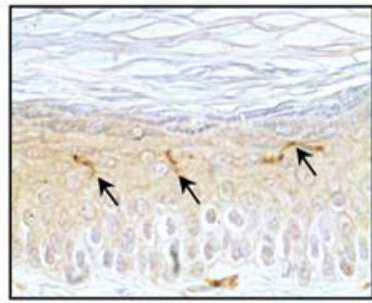

D (nNOS -/-)
B.

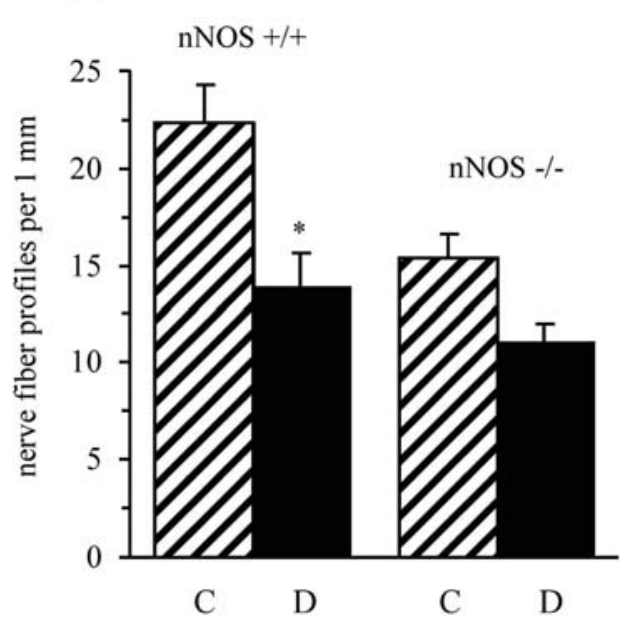

Figure 4. Intraepidermal nerve fiber profiles in control and diabetic wild-type and nNOS ${ }^{-/}$mice. (A) Representative images of intraepidermal nerve fiber profiles, magnification $\times 200$; (B) skin fiber density. Mean $\pm \mathrm{SEM}, \mathrm{n}=8-11$ per group. $\mathrm{C}$, control mice; $\mathrm{D}$, diabetic mice. " $\mathrm{p}<0.05$ vs control mice.
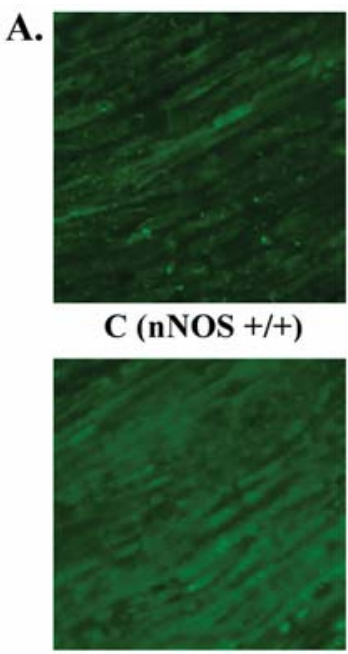

C (nNOS -/-)

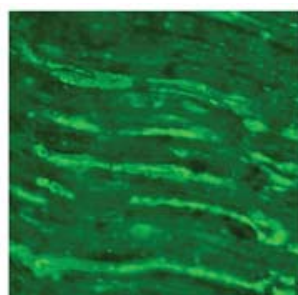

D (nNOS +/+)

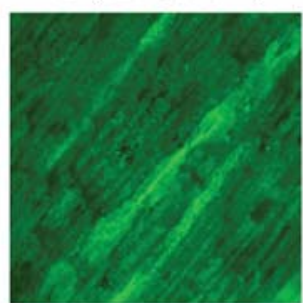

D (nNOS -/-)

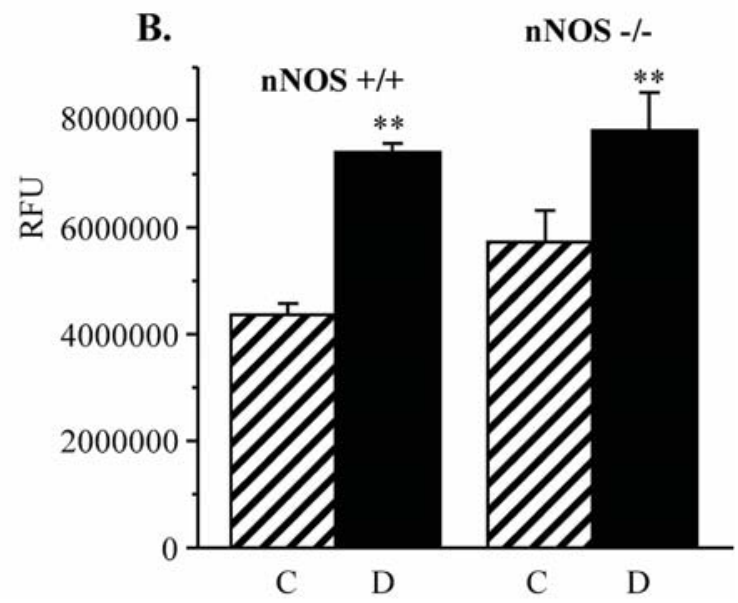

Figure 5. (A) Representative microphotographs of immunofluorescent staining of nitrotyrosine in sciatic nerves of control and diabetic wild-type and nNOS ${ }^{-1 /}$ mice. Magnification x 40. (B) Nitrotyrosine fluorescence counts in sciatic nerves of control and diabetic wild-type and $\mathrm{nNOS}{ }^{-/-}$mice. Mean $\pm \mathrm{SEM}, \mathrm{n}=7-11 \mathrm{per}$ group. C, control mice; D, diabetic mice. ${ }^{* *}$ p $<0.01$ vs non-diabetic control mice.

Non-diabetic nNOS $^{-/-}$mice displayed $47 \%$ reduction in tactile response thresholds, compared with non-diabetic wildtype mice (Fig. 3). Diabetic wild-type mice developed clearly manifest tactile allodynia, whereas tactile response threshold were similarly reduced in non-diabetic and diabetic $\mathrm{nNOS}^{-/-}$ mice, compared with wild-type controls.

INFD was reduced by $38 \%$ in diabetic wild-type mice and by $27 \%$ in diabetic NOS $^{-/-}$mice compared with the corresponding controls ( $\mathrm{p}<0.05$ for both comparisons, Fig. 4). Note, however, that nNOS gene deficiency was associated with a $32 \%$ decrease in INFD in non-diabetic mice.

NT immunofluorescence was $31 \%$ higher in non-diabetic $\mathrm{nNOS}^{-/-}$mice compared with non-diabetic wild-type mice, but the difference between two non-diabetic groups did not achieve statistical significance. NT immunofluorescence increased by 69 and $37 \%$ in the sciatic nerves of diabetic wild-type and $\mathrm{nNOS}^{-/-}$mice, respectively, compared with the corresponding non-diabetic controls $(\mathrm{p}<0.01$, Fig. 5). DRG NT immunofluorescence was comparable in non-diabetic wild-type and $\mathrm{nNOS}^{-/-}$mice (Fig. 6). It was increased by $56 \%$ in diabetic wild-type mice compared with non-diabetic controls $(\mathrm{p}<0.01)$. In contrast, diabetic $\mathrm{nNOS}^{-/-}$mice were protected against peroxynitrite injury in DRG and maintained nitrotyrosine immunoreactivity at the level detected in nondiabetic mice.

PAR fluorescence was similar in DRG of non-diabetic wild-type and $\mathrm{nNOS}^{-/-}$mice (Fig. 7). It was $23 \%$ higher in DRG of diabetic wild-type mice compared with non-diabetic controls $(\mathrm{p}<0.01)$. In contrast, diabetic $\mathrm{nNOS}^{-/-}$mice displayed normal DRG PAR immunofluorescence (Fig. 8). The 

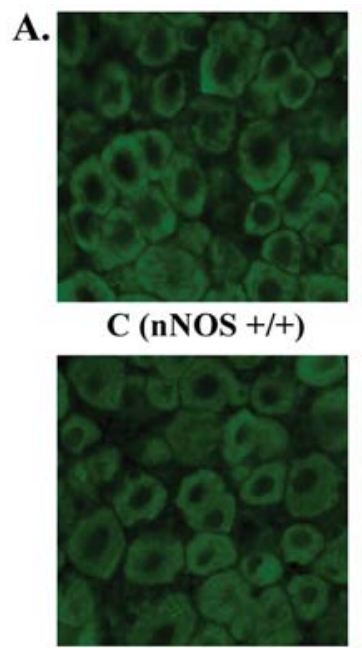

C (nNOS -/-)

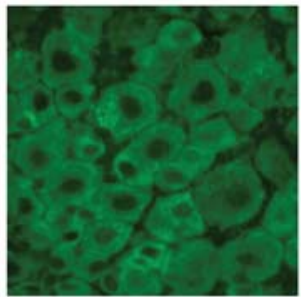

D $($ nNOS $+/+)$

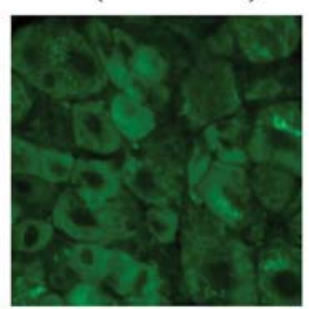

D (nNOS -/-)

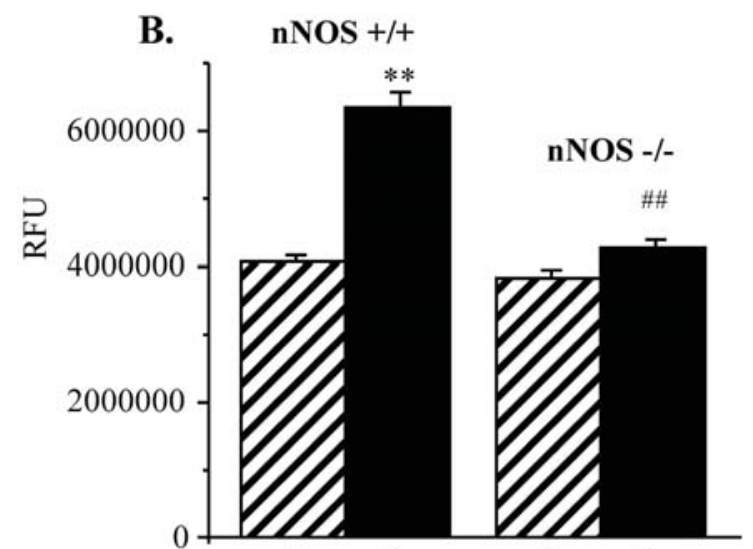

C

D

C

$\mathrm{D}$

Figure 6. (A) Representative microphotographs of immunofluorescent staining of nitrotyrosine in dorsal root ganglia of control and diabetic wild-type and $\mathrm{nNOS}^{-/}$mice. Magnification x40. (B) Nitrotyrosine fluorescence counts in dorsal root ganglia of control and diabetic wild-type and nNOS ${ }^{-/-}$mice. Mean \pm SEM, $\mathrm{n}=7-11$ per group. $\mathrm{C}$, control mice; $\mathrm{D}$, diabetic mice. ${ }^{* *} \mathrm{p}<0.01$ vs non-diabetic control mice. ${ }^{\# \#} \mathrm{p}<0.01$ vs diabetic wild-type mice.

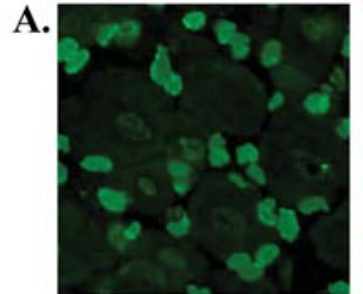

C $($ nNOS +/+)

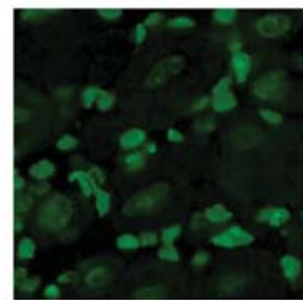

C (nNOS -/-)

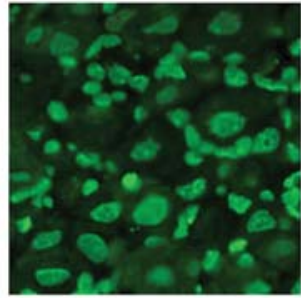

D $($ nNOS $+/+)$

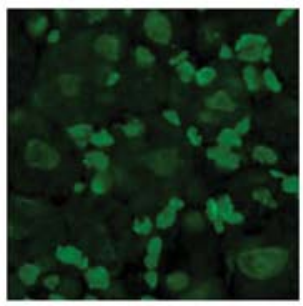

D (nNOS -/-)

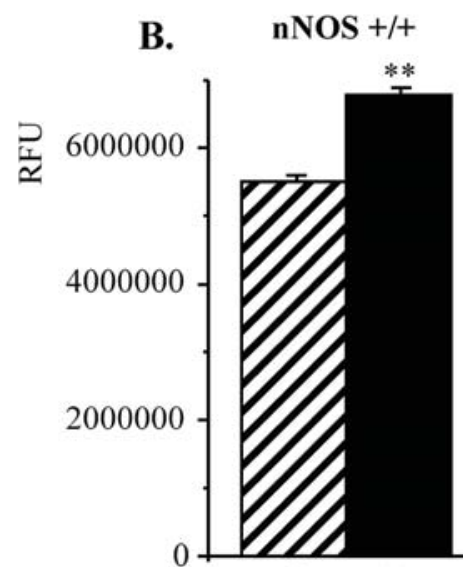

$\mathrm{C}$

$\mathrm{D}$
nNOS -/-

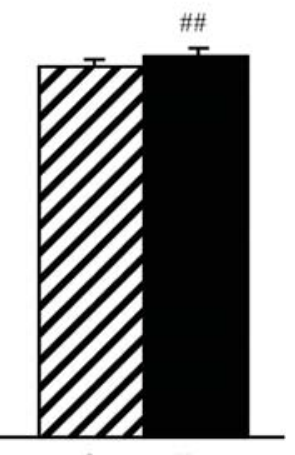

$\mathrm{C}$

$\mathrm{D}$

Figure 7. (A) Representative microphotographs of immunofluorescent staining of poly(ADP-ribose) in dorsal root gangia of control and diabetic wild-type and $\mathrm{nNOS}^{-/}$mice. Magnification x40. (B) Poly(ADP-ribose) fluorescence counts in dorsal root ganglia of control and diabetic wild-type and nNOS ${ }^{-/}$mice. Mean \pm SEM, $n=7-11$ per group. $C$, control mice; $\mathrm{D}$, diabetic mice. ${ }^{* *} \mathrm{p}<0.01$ vs non-diabetic control mice. ${ }^{\# \#} \mathrm{p}<0.01$ vs diabetic wild-type mice.

percentage of DRG neurons with weak PAR immunofluorescence was lower, and of those with moderate and intense immunofluorescence higher in diabetic wild-type mice compared with the corresponding control group. nNOS gene deficiency reduced the percentage of neurons with moderate and intense PAR fluorescence and increased the percentage of neurons with weak PAR fluorescence in diabetic mice.

\section{Discussion}

nNOS is expressed in many cell types in peripheral nervous system including Schwann cells of peripheral nerve (36), DRG neurons $(37,38)$, and motoneurons, oligodendrocytes, and astrocytes of spinal cord $(39,40)$. One can not exclude that it is also expressed in vasa nervorum considering recent report of the presence of nNOS in vascular endothelium (41). Note, that nNOS is constitutively expressed in some types of neurons, and can be induced in others (42). Sciatic nerve (43) or pelvic nerve (44) transection induced nitric oxide synthase expression in small to medium sized DRG neurons suggesting that this change may be limited to, or most prominent in, C-fiber afferents.

The findings of the present study suggest that nNOS is required for maintaining the normal peripheral nerve function and small sensory nerve fibre innervation. The latter is not surprising because nNOS is the main producer of nitric oxide which serves as a neurotransmitter in PNS (45). nNOS gene deficiency in non-diabetic mice affected both large and small sensory nerve fibers and was associated with reduction in sensory nerve conduction velocity, tactile response thresholds, 
A.

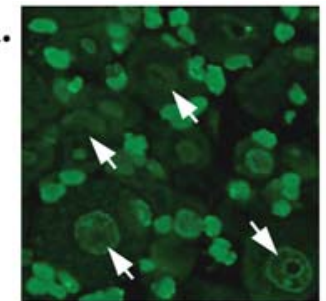

$\mathrm{C}(\mathrm{nNOS}+/+)$

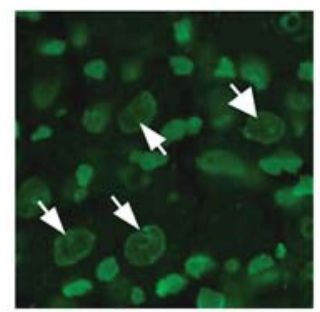

$\mathrm{C}(\mathrm{nNOS}-/-)$

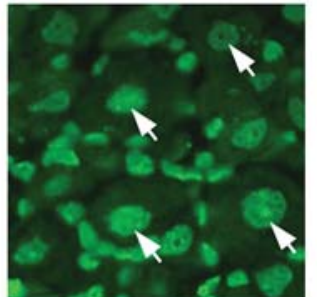

$\mathrm{D}(\mathrm{nNOS}+/+)$

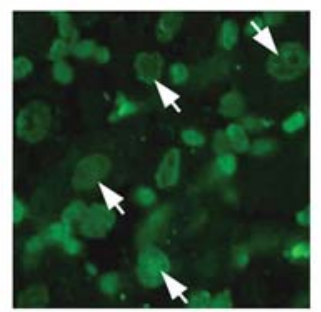

D (nNOS -/-)

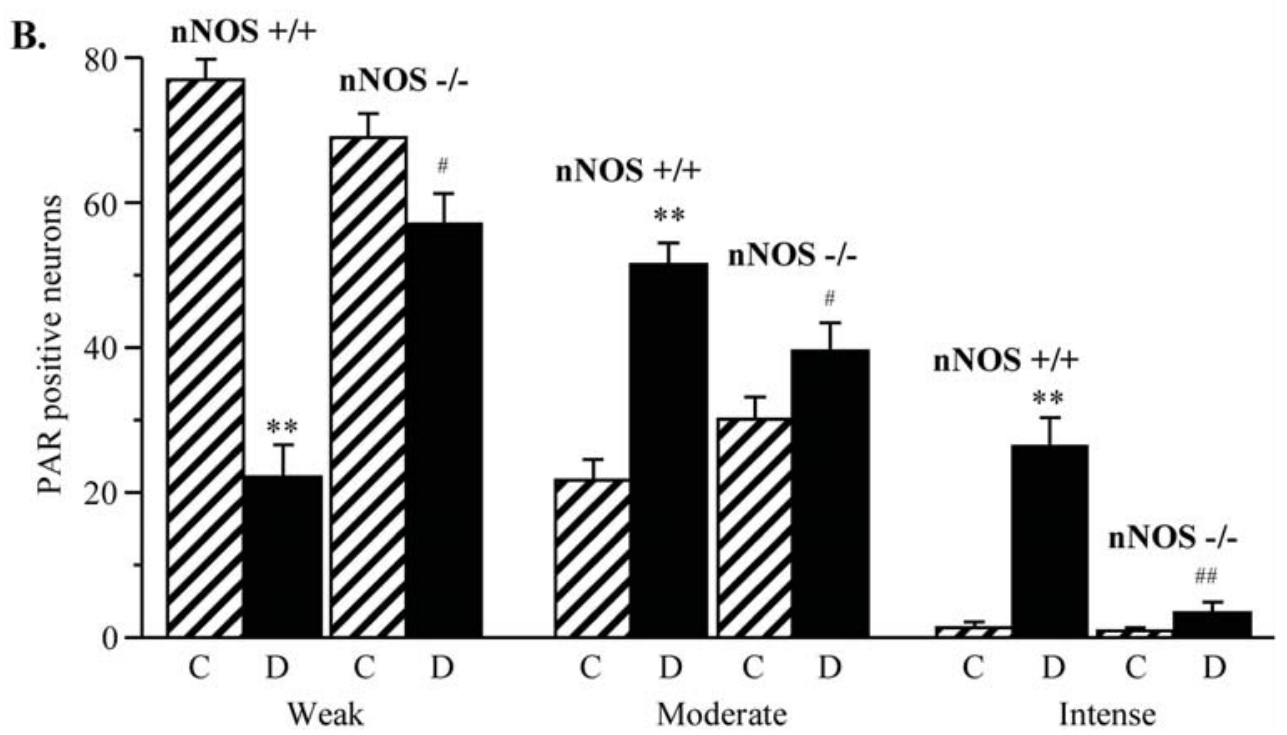

Figure 8. (A) Representative microphotographs of immunofluorescent staining of poly(ADP-ribose) in dorsal root gangion neurons of control and diabetic wild-type and $\mathrm{nNOS}^{-/}$mice. Magnification x100. (B) Percentage of dorsal root ganglion neurons with weak, moderate, and intense poly(ADP-ribose) immunofluorescence in experimental groups. The number of dorsal root ganglion neurons with weak, moderate and intense poly(ADP-ribose) immunofluorescence was expressed as a percentage of neurons with identifiable poly(ADP-ribose) immunofluorescence in the dorsal root ganglia of control and diabetic wild-type and $\mathrm{nNOS}^{-/-}$mice. Mean $\pm \mathrm{SEM}, \mathrm{n}=8-11$ per group. $\mathrm{C}$, control mice; $\mathrm{D}$, diabetic mice. ${ }^{* *} \mathrm{p}<0.01$ vs non-diabetic control mice; $\#, \# \#<0.01$ vs diabetic wild-type mice.

and loss of intraepidermal innervation. Other report suggests that nNOS plays a critical role in Schwann cells proliferation during peripheral nerve regeneration (46). On the other hand, nNOS overexpression was implicated in neuropathic pain resulting from nerve injury or peripheral inflammation $(47,48)$.

nNOS expression was reduced in sciatic nerve of C57BLKS/J- $m^{+/+}$Lepr $^{d b}$ homozygous (db/db) mice compared with non-diabetic controls, and in high glucose-exposed cultured mouse Schwann cells compared with the cells cultured at normal glucose concentration (36). The 3-hydroxy3-methyl-glutaryl-CoA reductase inhibitor rosuvastatin reversed reduction of nNOS expression in sciatic nerves of diabetic mice, and prevented high glucose-induced nNOS down-regulation in mouse Schwann cells, by mechanisms that involved phosphoinositide 3-kinase and phosphorylation of Akt (36). In the same study, co-treatment of diabetic mice with rosuvastatin and the selective nNOS inhibitor 1,2trifluoromethylphenyl imidazole, blunted beneficial effects of rosuvastatin on MNCV and SNCV deficits, thermal sensitivity, and nerve vascularity which suggests an important role for nNOS-derived NO in peripheral nerve function. Of interest, NOS enzymatic activity in DRG was increased rather than reduced in rats with STZ-diabetes of 12-month duration (37). This activation, however, was not due to an increase in nNOS mRNA expression or immunoreactivity.

In the present study, diabetic wild-type mice displayed clearly manifest nitrosative stress in both peripheral nerve and DRG. nNOS gene deficiency prevented diabetes-induced peroxynitrite injury manifest by nitrotyrosine accumulation, in DRG neurons, but not in peripheral nerve which is indica- 
tive of different roles of nNOS-derived NO in peroxynitrite formation in these two tissue-sites of PDN. Despite the lack of neuronal nitrosative stress, diabetic $\mathrm{nNOS}^{-/-}$mice displayed reduction in MNCV and $\mathrm{SNCV}$, sensory disorders, and intraepidermal nerve fiber loss, although nerve conduction deficits and thermal hypoalgesia were less severe in diabetic $\mathrm{nNOS}^{-/-}$mice, than in diabetic wild-type mice. Note, that in our previous study (11), diabetic iNOS $^{-/-}$mice which were protected from nitrosative stress in peripheral nerve, but not DRG neurons, preserved normal nerve conduction velocities and thermal sensitivity. These findings suggest that nitrosative stress in peripheral nerve, rather than DRG neurons, contributes to the development of early PDN. The roles iNOS and $\mathrm{nNOS}$ in advanced PDN still remain to be established.

The importance of oxidative-nitrosative stress in peripheral nerve, but not DRG, in early PDN is further supported by the pattern of changes in PARP activity. Evidence for the important role for PARP activation in diabetic complications including endothelial dysfunction (49), cardiomyopathy (50), peripheral (14-17) and autonomic (51) neuropathy, nephropathy $(52)$, and retinopathy $(53,54)$ is emerging. Accumulation of poly(ADP-ribosyl)ated proteins, a sign of PARP activation, has been documented in peripheral nerve and DRG neurons of animal models of Type 1 and Type 2 diabetes and high glucose-exposed cultured human Schwann cells (6-11,14-17,22,35,55) PARP activation has been implicated in neurovascular dysfunction, motor and sensory nerve conduction velocity deficits, peripheral nerve energy failure, thermal hyper- and hypoalgesia, mechanical hypoalgesia, tactile allodynia, and intraepidermal nerve fiber loss characteristic for PDN $(14-17,56)$. In the present study, PARP activation was clearly manifest in both sciatic nerve and DRG of diabetic wild-type mice consistent with our previous studies $(6,8,9,11)$. Diabetic nNOS mice displayed near normal poly(ADP-ribosyl)ated fluorescence in DRG neurons, but, nevertheless, developed PDN. In contrast, iNOS gene deficiency did not protect against diabetes-associated accumulation of poly(ADP-ribosyl)ated proteins in DRG neurons (11). However, diabetic iNOS $^{-/-}$mice displayed near normal poly(ADP-ribosyl)ation in peripheral nerve, and had normal nerve conduction and milder sensory neuropathy than wild-type mice with diabetes of similar severity and duration (11). These findings suggest that PARP activation in peripheral nerve rather than DRG neurons plays a pathogenetic role in early diabetic neuropathy. This conclusion is consistent with our findings in the diabetic rat model $(10,16)$. Rats with 4-6-weeks STZ-diabetes displayed PARP activation manifest by increased poly(ADP-ribosyl)ated protein immunoreactivity $(14,15)$, immunofluorescence $(16)$ or expression by Western blot analysis (57) in the peripheral nerve, but not DRG [(10), Obrosova et al, unpublished data). Nevertheless, PARP inhibitor treatment of rats with short-term (4-6 weeks) STZdiabetes counteracted multiple functional manifestations of PDN (14-16) which, again, suggests that PARP activation in peripheral nerve [i.e., endothelial and Schwann cells (14)], but not DRG neurons, contributes to the development of early PDN.

In conclusion, nNOS is required for maintaining the normal peripheral nerve function and small sensory nerve fibre innervation and appears to be the main source of nitric oxide for diabetes-associated peroxynitrite formation in DRG neurons. In contrast, this isoform does not seem to contribute to peroxynitrite formation in diabetic peripheral nerve. nNOS gene deficiency does not protect from development of nerve conduction deficit, sensory neuropathy, and intraepidermal nerve fiber loss. These findings, together with our previous studies, suggest that oxidative-nitrosative stress in axons and Schwann cells, rather than DRG neurons, plays a major role in, at least, early PDN.

\section{Acknowledgements}

The study was supported by the American Diabetes Association Research Grant 7-05-RA-102, the Juvenile Diabetes Research Foundation International Grant 1-2005223, the National Institutes of Health Grant DK 071566-01 (all to I.G.O.), and the Intramural Research Program of the National Institutes of Health/National Institute of Alcohol Abuse and Alcoholism (to P.P.).

\section{References}

1. Virág L, Szabó E, Gergely $\mathrm{P}$ and Szabó C: Peroxynitriteinduced cytotoxicity: mechanism and opportunities for intervention. Toxicol Lett 140-141: 113-124, 2003.

2. Pacher P, Obrosova IG, Mabley JG and Szabó C: Role of nitrosative stress and peroxynitrite in the pathogenesis of diabetic complications. Emerging new therapeutical strategies. Curr Med Chem 12: 267-275, 2005.

3. Pacher P, Beckman JS and Liaudet L: Nitric oxide and peroxynitrite in health and disease. Physiol Rev 87: 315-424, 2007.

4. Szabó C, Ischiropoulos H and Radi R: Peroxynitrite: biochemistry, pathophysiology and development of therapeutics. Nat Rev Drug Discov 6: 662-680, 2007.

5. Szabó C, Mabley JG, Moeller SM, Shimanovich R, Pacher P, Virag L, Soriano FG, van Duzer JH, Williams W, Salzman AL and Groves JT: Part I. Pathogenetic role of peroxynitrite in the development of diabetes and diabetic vascular complications: studies with FP15, a novel potent peroxynitrite decomposition catalyst. Mol Med 8: 571-580, 2002.

6. Obrosova IG, Mabley JG, Zsengellér Z, Charniauskaya T, Abatan OI, Groves JT and Szabó C: Role for nitrosative stress in diabetic neuropathy: evidence from studies with a peroxynitrite decomposition catalyst. FASEB J 19: 401-403, 2005.

7. Vareniuk I, Pavlov IA, Drel VR, Lyzogubov VV, Inytska O, Bell SR, Tibrewala J, Groves JT and Obrosova IG: Nitrosative stress and peripheral diabetic neuropathy in leptin-deficient (ob/ob) mice. Exp Neurol 205: 425-436, 2007.

8. Drel VR, Pacher P, Vareniuk I, Pavlov I, Ilnytska O, Lyzogubov VV, Tibrewala J, Groves JT and Obrosova IG: A peroxynitrite decomposition catalyst counteracts sensory neuropathy in streptozotocin-diabetic mice. Eur J Pharmacol 569: 48-58, 2007.

9. Drel VR, Pacher P, Vareniuk I, Pavlov IA, Ilnytska O, Lyzogubov VV, Bell SR, Groves JT and Obrosova IG: Evaluation of the peroxynitrite decomposition catalyst Fe(III) tetra-mesitylporphyrin octasulfonate on peripheral neuropathy in a mouse model of type 1 diabetes. Int J Mol Med 20: 783-792, 2007.

10. Obrosova IG, Drel VR, Oltman CL, Mashtalir N, Tibrewala J, Groves JT and Yorek MA: Role of nitrosative stress in early neuropathy and vascular dysfunction in streptozotocin-diabetic rats. Am J Physiol Endocrinol Metab 293: E1645-E1655, 2007.

11. Vareniuk I, Pavlov IA and Obrosova IG: Inducible nitric oxide synthase gene deficiency counteracts multiple manifestations of peripheral neuropathy in a streptozotocin-induced mouse model of diabetes. Diabetologia 51: 2126-2133, 2008.

12. Nangle MR, Cotter MA and Cameron NE: Effects of the peroxynitrite decomposition catalyst, FeTMPyP, on function of corpus cavernosum from diabetic mice. Eur J Pharmacol 502: 143-148, 2004. 
13. Zheng L, Du Y, Miller C, Gubitosi-Klug RA, Ball S, Berkowitz BA and Kern TS: Critical role of inducible nitric oxide synthase in degeneration of retinal capillaries in mice with streptozotocin-induced diabetes. Diabetologia 50: 1987-1996, 2007.

14. Obrosova IG, Li F, Abatan OI, Forsell MA, Komjati K, Pacher P, Szabo C and Stevens MJ: Role of poly(ADP-ribose) polymerase activation in diabetic neuropathy. Diabetes 53: 711-720, 2004.

15. Li F, Szabó C, Pacher P, Southan GJ, Abatan OI, Charniauskaya T, Stevens MJ and Obrosova IG: Evaluation of orally active poly(ADP-ribose) polymerase inhibitor in streptozotocin-diabetic rat model of early peripheral neuropathy. Diabetologia 47: 710-717, 2004.

16. Ilnytska O, Lyzogubov VV, Stevens MJ, Drel VR, Mashtalir N, Pacher P, Yorek MA and Obrosova IG: Poly(ADP-Ribose) polymerase inhibition alleviates experimental diabetic sensory neuropathy. Diabetes 55: 1686-1694, 2006.

17. Obrosova IG, Xu W, Lyzogubov VV, Ilnytska O, Mashtalir N, Vareniuk I, Pavlov IA, Zhang J, Slusher B and Drel VR: PARP inhibition or gene deficiency counteracts intraepidermal nerve fiber loss and neuropathic pain in advanced diabetic neuropathy. Free Radic Biol Med 44: 972-981, 2008.

18. Cotter MA and Cameron NE: Effect of the NAD(P)H oxidase inhibitor, apocynin, on peripheral nerve perfusion and function in diabetic rats. Life Sci 73: 1813-1824, 2003.

19. Inkster ME, Cotter MA and Cameron NE: Treatment with the xanthine oxidase inhibitor, allopurinol, improves nerve and vascular function in diabetic rats. Eur J Pharmacol 561: 63-71, 2007.

20. Davidson EP, Kleinschmidt TL, Oltman CL, Lund DD and Yorek MA: Treatment of streptozotocin-induced diabetic rats with AVE7688, a vasopeptidase inhibitor: effect on vascular and neural disease. Diabetes 56: 355-362, 2007

21. Oltman CL, Davidson EP, Coppey LJ, Kleinschmidt TL, Lund DD, Adebara ET and Yorek MA: Vascular and neural dysfunction in Zucker diabetic fatty rats: a difficult condition to reverse. Diabetes Obes Metab 10: 64-74, 2008.

22. Obrosova IG, Drel VR, Pacher P, Ilnytska O, Wang ZQ, Stevens MJ and Yorek MA: Oxidative-nitrosative stress and poly(ADP-ribose) polymerase (PARP) activation in experimental diabetic neuropathy: the relation is revisited. Diabetes 54: 3435-3441, 2005.

23. Low PA and Nickander KK: Oxygen free radical effects in sciatic nerve in experimental diabetes. Diabetes 40: 873-877, 1991

24. Stevens MJ, Obrosova I, Cao X, van Huysen C and Greene DA: Effects of DL-alpha-lipoic acid on peripheral nerve conduction, blood flow, energy metabolism, and oxidative stress in experimental diabetic neuropathy. Diabetes 49: 1006-1015, 2000 .

25. Cameron NE, Eaton SE, Cotter MA and Tesfaye S: Vascular factors and metabolic interactions in the pathogenesis of diabetic neuropathy. Diabetologia 44: 1973-1988, 2001.

26. Cotter MA, Ekberg K, Wahren $J$ and Cameron NE: Effects of proinsulin $\mathrm{C}$-peptide in experimental diabetic neuropathy: vascular actions and modulation by nitric oxide synthase inhibition. Diabetes 52: 1812-1817, 2003.

27. Yagihashi S, Yamagishi SI, Wada Ri R, Baba M, Hohman TC, Yabe-Nishimura $C$ and Kokai Y: Neuropathy in diabetic mice overexpressing human aldose reductase and effects of aldose reductase inhibitor. Brain 124: 2448-2458, 2001.

28. Ho EC, Lam KS, Chen YS, Yip JC, Arvindakshan M, Yamagishi S, Yagihashi S, Oates PJ, Ellery CA, Chung SS and Chung SK: Aldose reductase-deficient mice are protected from delayed motor nerve conduction velocity, increased c-Jun NH2terminal kinase activation, depletion of reduced glutathione, increased superoxide accumulation, and DNA damage. Diabetes 55: 1946-1953, 2006

29. Christianson JA, Ryals JM, Johnson MS, Dobrowsky RT and Wright DE: Neurotrophic modulation of myelinated cutaneous innervation and mechanical sensory loss in diabetic mice. Neuroscience 145: 303-313, 2007.

30. Muller KA, Ryals JM, Feldman EL and Wright DE: Abnormal muscle spindle innervation and large-fiber neuropathy in diabetic mice. Diabetes 57: 1693-1701, 2008.

31. Beiswenger KK, Calcutt NA and Mizisin AP: Dissociation of thermal hypoalgesia and epidermal denervation in streptozotocin-diabetic mice. Neurosci Lett 442: 267-272, 2008 .
32. Toth C, Rong LL, Yang C, Martinez J, Song F, Ramji N, Brussee V, Liu W, Durand J, Nguyen MD, Schmidt AM and Zochodne DW: Receptor for advanced glycation and products (RAGEs) and experimental diabetic neuropathy. Diabetes 57: 1002-1017, 2008.

33. Kellogg AP, Wiggin TD, Larkin DD, Hayes JM, Stevens MJ and Pop-Busui R: Protective effects of cyclooxygenase-2 gene inactivation against peripheral nerve dysfunction and intraepidermal nerve fiber loss in experimental diabetes. Diabetes 56: 2997-3005, 2007.

34. Jagtap P and Szabo C: Poly(ADP-ribose) polymerase and the therapeutic effects of its inhibitors. Nat Rev Drug Discov 4: 421-440, 2005

35. Obrosova IG, Ilnytska O, Lyzogubov VV, Pavlov IA, Mashtalir N, Nadler JL and Drel VR: High-fat diet induced neuropathy of pre-diabetes and obesity: effects of 'healthy' diet and aldose reductase inhibition. Diabetes 56: 2598-2608, 2007.

36. Ii M, Nishimura H, Kusano KF, Qin G, Yoon YS, Wecker A, Asahara T and Losordo DW: Neuronal nitric oxide synthase mediates statin-induced restoration of vasa nervorum and reversal of diabetic neuropathy. Circulation 112: 93-102, 2005.

37. Zochodne DW, Verge VM, Cheng C, Höke A, Jolley C, Thomsen K, Rubin I and Lauritzen M: Nitric oxide synthase activity and expression in experimental diabetic neuropathy. $\mathrm{J}$ Neuropathol Exp Neurol 59: 798-807, 2000.

38. Burnand RC, Price SA, McElhaney M, Barker D and Tomlinson DR: Expression of axotomy-inducible and apoptosis-related genes in sensory nerves of rats with experimental diabetes. Brain Res Mol Brain Res 132: 235-240, 2004.

39. Wu W, Liuzzi FJ, Schinco FP, Depto AS, Li Y, Mong JA, Dawson TM and Snyder SH: Neuronal nitric oxide synthase is induced in spinal neurons by traumatic injury. Neuroscience 61: 719-726, 1994

40. Cheng C, Li X, Gao S, Niu S, Chen M, Qin J, Guo Z, Zhao J and Shen A: Expression of CAPON after spinal cord injury in rats. J Mol Neurosci 34: 109-119, 2008.

41. Capettini L, Cortes SF, Gomes MA, Silva G, Pesquero JL, Lopes MJ, Teixeira MM and Lemos VS: Neuronal nitric oxide synthase-derived hydrogen peroxide is a major endotheliumdependent relaxing factor. Am J Physiol Heart Circ Physiol 295: H2503-H2511, 2008.

42. Vizzard MA, Erdman SL and De Groat WC: Increased expression of neuronal nitric oxide synthase (NOS) in visceral neurons after nerve injury. J Neurosci 15: 4033-4045, 1995.

43. Vizzard MA, Erdman SL and De Groat WC: Increased expression of neuronal nitric oxide synthase in dorsal root ganglion neurons after systemic capsaicin administration. Neuroscience 67: 1-5, 1995.

44. Vizzard MA, Erdman SL and De Groat WC: The effect of rhizotomy on NADPH diaphorase staining in the lumbar spinal cord of the rat. Brain Res 607: 349-353, 1993.

45. Garthwaite J: Concepts of neural nitric oxide-mediated transmission. Eur J Neurosci 27: 2783-802, 2008.

46. Shen A, Gao S, Ben Z, Wang H, Jia J, Tao T, Niu S, Li X and Cheng C: Identification and potential role of PSD-95 in Schwann cells. Neurol Sci 29: 321-330, 2008.

47. Jin XG, He SQ, Yan XT, Zhang G, Wan L, Wang J, Li Y, Tian X, Tian $Y$ and Luo A: Variants of neural nitric oxide synthase in the spinal cord of neuropathic rats and their effects on nuclear factor-kappaB (NF-kappaB) activity in PC12 Cells. J Pain 10: 80-89, 2009.

48. Lam HH, Hanley DF, Trapp BD, Saito S, Raja S, Dawson TM and Yamaguchi $\mathrm{H}$ : Induction of spinal cord neuronal nitric oxide synthase (NOS) after formalin injection in the rat hind paw. Neurosci Lett 210: 201-214, 1996.

49. Garcia Soriano F, Virag L, Jagtap P, Szabo E, Mabley JG, Liaudet L, Marton A, Hoyt DG, Murthy KG, Salzman AL, Southan GJ and Szabo C: Diabetic endothelial dysfunction: the role of poly(ADP-ribose) polymerase activation. Nat Med 7: 108-113, 2001

50. Pacher P, Liaudet L, Soriano FG, Mabley JG, Szabó E and Szabó C: The role of poly(ADP-ribose) polymerase activation in the development of myocardial and endothelial dysfunction in diabetes. Diabetes 51: 514-521, 2002.

51. Gibson TM, Cotter MA and Cameron NE: Effects of poly(ADPribose) polymerase inhibition on dysfunction of non-adrenergic non-cholinergic neurotransmission in gastric fundus in diabetic rats. Nitric Oxide 15: 344-350, 2006. 
52. Szabó C, Biser A, Benko R, Böttinger E and Suszták K: Poly(ADP-ribose) polymerase inhibitors ameliorate nephropathy of type 2 diabetic Leprdb/db mice. Diabetes 55: 3004-3012, 2006.

53. Obrosova IG, Minchenko AG, Frank RN, Seigel GM, Zsengeller Z, Pacher P, Stevens MJ and Szabó C: Poly(ADPribose) polymerase inhibitors counteract diabetes- and hypoxiainduced retinal vascular endothelial growth factor overexpression. Int J Mol Med 14: 55-64, 2004.

54. Zheng L, Szabó C and Kern TS: Poly(ADP-ribose) polymerase is involved in the development of diabetic retinopathy via regulation of nuclear factor-kappaB. Diabetes 53: 2960-2967, 2004
55. Stevens MJ, Li F, Drel VR, Abatan OI, Kim H, Burnett D, Larkin D and Obrosova IG: Nicotinamide reverses neurological and neurovascular deficits in streptozotocin diabetic rats. J Pharmacol Exp Ther 320: 458-464, 2007.

56. Obrosova IG and Julius UA: Role for poly(ADP-ribose) polymerase activation in diabetic nephropathy, neuropathy and retinopathy. Curr Vasc Pharmacol 3: 267-283, 2005.

57. Li F, Drel VR, Szabó C, Stevens MJ and Obrosova IG: Lowdose poly(ADP-ribose) polymerase inhibitor-containing combination therapies reverse early peripheral diabetic neuropathy. Diabetes 54: 1514-1522, 2005. 